\title{
THE CONTRIBUTION OF CLINICAL PSYCHOLOGY TO SPORTS MEDICINE
}

\author{
M. YAFFÉ, PhD
}

Senior Clinical Psychologist, Guy's Hospital

Clinical sports psychology has over the past few years evolved into a distinct speciality and comprises basically five related areas:

a mental practice and rehearsal

b stress management

c pain control in injury

d counselling

e evaluation of predictive psychological factors associated with success in particular sports. The theoretical orientation and framework within clinical psychology applied to sport that has shown most promise is the behavioural one. Techniques designated as behaviour therapy provide a unique approach to the assessment and modification of behavioural problems; they are derived from empirical research and remain accountable, as their therapeutic effectiveness is subjected to continued research (Rimm and Masters, 1980). This sort of accountability is sadly lacking in most traditional psychotherapies.

\section{STRESS}

In order to explain the application of behavioural techniques in sport it is useful to use one area to exemplify the procedures. As stress is a central problem, particularly in top-level sport, this will be the focus in describing the range of available methods of assessment and modification, although all the procedures are relevant to other behavioural sports problems.

One of the common features of stress and the anxiety that usually results is the feeling of not being able to comprehend and control what is happening. CarrKaffashan, et al (1978) have developed a programme for dealing with both these aspects, and their approach is followed closely in this paper. They describe the A-B-C model of pinpointing stress and the responses to it in an attempt to understand the experience; this helps to diffuse the initiation of negative, usually frightening, feelings and enables systematic solutions to real problems in sports performance. In this model $A$ refers to antecedant or precipitant external factors as a source of stress; B is the person's behaviour or beliefs as a result of stress; and $C$ denotes the consequences or combination of bodily sensations of emotional reactions that occur in the light of the stressful situation.

The first step in pinpointing the sources of stress and its concomitant anxiety, is to understand what preceded the feeling of anxiety, being under pressure or overwhelmed. Questions such as: On what occasions prior to or during competition did I have this feeling? What specific stages of competition or time of day did it occur? Where was I exactly when it did so? What exactly was I doing? Who was there with me at the time? help us to clarify these antecedants.

The second step, as Carr-Kaffashan, et al (1978) point out, involves pinpointing those behaviours, thoughts and beliefs that occur in reaction to the stressful antecedant event. Although we are not always aware of them, thoughts and actions are the bridge between stress and anxiety: how we talk to ourselves and what we do essentially determines our emotional reactions. It is the interpretation of events, not simply the events themselves, that lead to these emotional responses, and so it is necessary to specify the nature of attendant thoughts and actions. Relevant questions that enable us to pinpoint these thoughts and the interpretation of stressful situations include the following: What was the person expecting to happen? What thoughts or imagery were present at the time? What doubts, preoccupations, or worries was the person reminded of? What was the person actually saying to him/herself? It is also necessary to ask what fundamental beliefs or assumptions are relevant in the situation? As for behaviour, one needs to ask about what was the person talking about (if in company), and what the person looked like under stress to others.

The third step involves an analysis of the nature and 
severity of the person's feelings. Clearly, people can react very differently to the same stressful situation, such as competing in Olympic Games. One might become nervous, sweaty and shake; another might get stomach ache and talk a lot; and yet a third might feel positive excitation and express confidence.

In order to tease out these relations it is useful to find out what sensations, or words are used to describe the experience, and then the degree, in terms of severity or intensity, to which these are expressed. Finding out about the magnitude of emotional reactions helps to understand how individuals are affected by specific stressful situations. Rating scales are used to determine this and Table I enables one to pinpoint with some precision sources of stress, intermediate thoughts and actions, and concomitant anxiety.

\section{Cognitive Restructuring}

Thoughts influence our feelings and actions; cognitive re-structuring is an effective way to: (1) get the competitor to become more aware of what he is saying to himself, and to identify his implicit assumptions and beliefs; (2) to apprehend the effort of their self-statements and beliefs on behaviour, feelings and motivation; and (3) to teach the person to say more accurate, nonjudgemental and generally helpful words to himself. There are several categories of cognitive events that need to be discussed:

1 Self-Statements A person's anxiety reaction to situations relates directly to what they say to themselves; a thought is juxtaposed between every happening in the real world and the emotional reaction to it. New thoughts leading to anxiety are negative, usually automatic, and determine how a person feels about the particular event and with respect to themselves; sometimes the effect is long-term, as negative thoughts increase the chances of future difficulties. Realistic and positive self-talk helps to reinforce the sportsman's ability to deal with competitive stress and reinforce the ability to handle new situations (Table II).

2 Catastrophising This is the phenomenon when a person magnifies or amplifies an event out of proportion

\section{TABLE I}

\section{A-B-C of pinpointing stress and anxiety (after Carr-Kaffashan, et al, 1978)}

\section{Antecedent $=$ Stress $=$ External Event}

WHEN? WHERE?

1 Date,

2 Time,

3 Location
WHAT? WHO?

4 What was I engaged in?

5 Who was there with me?

FICTIONAL EXAMPLE IN SPORT

121 July 1978

2 2.30 p.m.

3 Swimming pool
4 Preparing for final breast stroke competition (Commonwealth Games)

5 Other competitors including current world champions
6 To win a large margin, maybe

$7 \mathrm{My}$ last encounter with the champion when he just beat me

81 never seem to do as well in big competitions compared to smaller ones or in training

9 "Go off very hard, and keep your rhythm"

$10 \mathrm{My}$ value as a person depends on how I do in competition

11 I was silent

12 Started to shake, heartbeat raised significantly
Consequences $=$ bodily sensations emotional reactions

\section{LABELS?} words best describe what I am feeling?

RATE?

14 How severe are the feelings I'm experiencing?

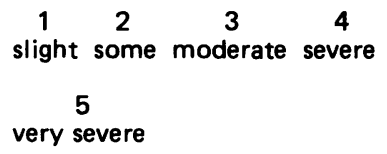

13 Nervous, light-headed 14 No. 4 
TABLE II

What you say to yourself - Examples in sport

Problem Category

1 Present form

2 Capabilities

3 Excuses

4 Goals/aims

5 Performance thoughts
Negative Monologues

"I'm not playing well enough these days."

"I'm not that good anyway."

"Maybe next time ..."

"I've really got to excel today."

"I can't stop thinking about the competition/match."

\section{Appropriate Monologues}

"Have patience - If I do the simple things I know I can do well, other skills will follow."

"If I wasn't any good, I wouldn't be in the squad/team."

"I'm the one in control and I'm going to make it happen right now."

"There's no point in setting unrealistic standards - I must start by doing what I know I'm good at."

"One mistake doesn't mean it's all over."

"Whenever I find myself thinking about the game/event, I quickly change the topic to some other pleasant experience."

rigid extremes is irrational, judgemental and likely to be self-destructive. Cognitive restructuring methods have shown the way in getting rid of these interference factors that often inhibit performance.

The focus of this paper has been on the recently evaluated cognitive aspect of anxiety, but it is necessary to take account of, albeit briefly, two related response systems: physiological and behavioural. Over the past few years psycho-physiological functioning has come under increasing scrutiny in clinical settings and a variety of anxiolytic techniques have been developed; these include progressive muscular relaxation, meditation and biofeedback (Yaffé, 1979) and details are available in any behaviour therapy textbook, such as that of Rimm and Masters, (1980). The behavioural component has been investigated in a similar fashion (Alberti and Emmons, 1973; Straub 1978 among others), and is of particular relevance for those competitors involved in team sports; techniques include communication skills and assertiveness training, and are designed to assist the individual to relate to others more effectively and to stand up to his rights and to help him achieve his goals without infringing upon the rights of others.

The marriage between sport and clinical psychology is a relatively recent one but the couple seem to be in for a long and interesting relationship.

\section{REFERENCES}

Alberti, R. E. and Emmons, M. L., 1978 "Your perfect right: A guide to assertive behaviour". (3rd Edition). Impact: San Luis Obispo, California.

Carr-Kaffashan, L., Ettin, M., Galano, J., Lehrer, P. and Roghberg, M., 1978 “Handbook of techniques for dealing with stress". Unpublished manuscript: Community Mental Health Centre, Rutgers Medical School, New Jersey. 
Rimm, D. C. and Masters, J. C., 1980 "Behaviour therapy: Techniques and empirical findings" (2nd Edition). Academic Press, New York.

Straub, W. F. (ed.), 1978 "Sport psychology: An analysis of athlete behaviour". Mouvement. Ithaca, N.Y.

Yaffé, M., 1979 "The contribution of psychology: An overview". Medisport, 1: 16-23.

\section{DISCUSSION}

Mr. Williams: Dr. Yaffé, do you believe that certain individuals however talented they may be, will never be champions?

Dr. Yaffé: Yes. The determinants of success are complex and multiple, and without behavioural analysis it is impossible to determine the importance of the event to the athlete.

Dr. Lucking: Dr. Yaffé, do you have any experience of the use of hypnosis?

Dr. Yaffé: I've no experience of using specific hypnotic techniques with athletes. I prefer active interventions, such as relaxation exercises and biofeedback. I do feel there is a role for hypnosis, especially for people who will not accept other measures.

\section{BOOK REVIEW}

Title: MEDICINE FOR SPORT

Editors: $\quad$ David French Apple and John Davis Cantwell

Publisher: $\quad$ Year Book Medical Publishers, Chicago, London, 1979 Price: $\mathbf{6 2 6 . 5 0}$

This small handsomely produced book is written by the team physician to the Atranta Hawks and the team physician to the Atlanta Braves. The transatlantic flavour is inescapable from the dedication page which includes "To ... S.C.B. who taught her baby brother how to fight back when cornered, and ... V.B. who emphasised the importance of a burning desire and led the Duke Blue Devils to the 1960 Atlantic Coast Conference Title."

The book is not intended as a textbook of sports medicine but is written for team physicians, trainers and health educators.

Since Dr. Cantwell is a cardiologist involved in rehabilitation and prevention there is an interesting emphasis on sport in middle age and on cardiology. However, the illustrations of coronary angiograms, ECGs and apex cardiograms may attract less attention from the prospective non-medical reader than those of the delightful lady marathon runners.

Although some sections are instructive, menstrual problems (nine lines) and drug abuse (no mention except in preface) are given less space than some rather routine advice on the management of pneumonia and many other problems which are not specific to sport and are managed no differently in the athlete. In the theraputic advice, American drug names which may be unfamiliar here are used and some of the recommended approach (blood pressure in both arms, auscultation of all four quadrants of the abdomen) might be classed as "defensive, litigation-conscious American medicine" in Britain.

The physical medicine and physiology sections are well illustrated and very readable although one might quibble with some statements such as "After 60-240 minutes of exercise the working muscle begins to oxidise fatty acid."

Altogether I found it an enjoyable and readable book. It is not a subtitute for a Sports Medicine Textbook and much of it will be unintelligible or inappropriate for trainers and health educators, but all will get something from it, if only a taste of Georgia.

D. Tunstall-Pedoe 